11-1-2005

\title{
Supporting and Preparing Future Decision-makers with the Needed Tools
}

\author{
Michael Wolf-Branigin \\ George Mason University, mwolfbra@gmu.edu
}

Follow this and additional works at: http://digitalcommons.wayne.edu/jmasm

Part of the Applied Statistics Commons, Social and Behavioral Sciences Commons, and the Statistical Theory Commons

\section{Recommended Citation}

Wolf-Branigin, Michael (2005) "Supporting and Preparing Future Decision-makers with the Needed Tools," Journal of Modern Applied Statistical Methods: Vol. 5 : Iss. 2 , Article 27.

DOI: $10.22237 /$ jmasm/1162355160

Available at: http://digitalcommons.wayne.edu/jmasm/vol5/iss2/27

This Regular Article is brought to you for free and open access by the Open Access Journals at DigitalCommons@WayneState. It has been accepted for inclusion in Journal of Modern Applied Statistical Methods by an authorized editor of DigitalCommons@WayneState. 


\title{
Supporting and Preparing Future Decision-makers with the Needed Tools
}

\author{
Michael Wolf-Branigin \\ George Mason University
}

Educational and social service researchers and evaluators continue to develop advanced statistical methods. To ensure that our students have the essential skills as they enter direct service, the focus must be on assuring that they learn readily understandable methods that are appropriate for small samples and use repeated measures.

Keywords: Non-parametric, small samples, repeated measures, decision-making, complexity

Introduction

After conducting behavioral health accreditation surveys over the past nine years and having been academia for five years, it is surprising how infrequently evaluators and administrators of these organizations use inferential statistics. Being able to cross over between the theoretical foundations of academia and the applied realm of social service organizations affords a unique perspective as to how organizations actually apply statistical methods. For example, in only two instances out of 46 opportunities over the past nine years did the social service organization's evaluator or quality assurance administrator apply any inferential statistic when analyzing the outcomes generated by their organization. When a test of significance was applied it was a Student's t-test in order to measure the improvement of client outcomes by comparing a cohort of intake scores to scores at time of program completion. In none of these cases did the organization's evaluator use distribution free statistics or a repeated measures approach to measure their client's outcomes.

Michael Wolf-Branigin is Associate professor of Social Work. His research interests include developmental disabilities and addictions, and applications of complex systems and information technology infusion. He has had prior experience in human service administration, governmental and nongovernmental consulting and academia.
Many readers of higher-level statistical and methodological journals are doctoral students with a teaching load of introductory research and statistical classes and must thereby remain cognizant of the analytical abilities and the statistical skills of the students that they need in order to encourage effective decisions. These students frequently enter their respective organization as administrators, consultants, or evaluators. While efforts have been initiated, for example the American Statistical Association (ASA) called for university statistical and other related departments to prepare statisticians on database management; IT through an accreditation process, and another ASA initiative is investigating the need to assure that statistical practitioners develop soft skills among statisticians to improve written, verbal and interpersonal skills (Batcher, 2005) their scope is limited. Additional supports need to be provided directly in the classrooms.

To emphasize the point, as the use of evidence-based practice and approach such as action research gain acceptance by practitioners and educators, gaps in the appropriate use of simple data analysis remain. As the methodological and statistical educators of these individuals, serious attention is needed to improve the link between research and practice. Given the complexities of many modern statistical techniques, now is an opportune time to reinforce some of the basic methods to assure that these future decision-makers are using correct methods. As an educator of students who eventually plan to become social work administrators, I suggest that there is a need to 
reflect and ask what useful information do these entry-level professional students gain that can be applied to their organizations or schools? When asked this, three problems frequently occur:

1. Failing to measure the same outcome variables at the beginning and end of an intervention or educational experience

2. Failing to apply tests of significance using repeated measures when appropriate

3. Committing Type II Errors.

Although the topics discussed below will appear obvious to most readers, these elementary concepts need strengthening. Most readers of this journal have experience instructing introductory research methods and statistics classes. Often these courses are for either higher-level undergraduate or master level social and educational services professionals. As instructors, it must be realized that a large proportion of the decision-makers within these social and education related services have a master's degree that required at best two research classes and possible one introductory statistics class. Their future employers assume that this rudimentary level of quantitative education provides a sufficient background for their employment.

Correct and robust application of statistics provides an essential tool for these students to use in assisting their organizations demonstrate statistically significant and measurable outcomes. These measurable outcomes additionally assist the organization in locating, securing and justifying further funding. This becomes increasingly important as these individuals work with smaller data sets in either classroom settings or smaller programs within educational and social service settings. Again, as an individual conducting accreditation surveys, quality improvement, and academic pursuits, it remains apparent how little information practitioners have on the use of robust methods.

Efforts of educators and practitioners in advanced methods can focus on several simple areas that will increase the likelihood that useful statistical techniques are applied in smaller settings, including: using repeated measures, increasing use of nonparametric tests, and providing an introduction to robust estimators. Although each of us knows these introductory techniques, below are the common and overlooked topics from introductory statistics classes that provide the greatest likelihood of assuring that future decision-makers apply appropriate methods.

\section{Use of Identical Measures}

First, the student needs to understand what their organization's monitoring and evaluation system is attempting to measure. Once understood, the student needs to assure that an organization uses the identical instrument at each measurement phase in order to guarantee that data on the same variable are collected. For example, in substance abuse treatment, organizations typically submits admission and discharge forms to their state funding source that in turn are reported to the Federal government. A variable such as "the number of days in the last month that the client has abused substances" is asked by most programs at admission and discharge.

Staff at the organizations can readily compare these measures at the different phases to identify actual changes in substance use by the consumer. Assuming that the organization tracks this information by each individual, use of repeated measures is a simple process. Qualitatively, social service, and educational institutions often have well conceptualized interventions and curricula that lead to positive outcomes; however, future decision-makers have not been provided with the simple tools to measure significant improvements.

\section{Apply the Correct Statistical Methodology}

As students prepare to enter the workforce, they need to identify and focus on the outcomes that their program is attempting to achieve. Most often organizations are attempting to compare groups of scores. These groups most often will be a group of scores before the persons served are active in treatment, during treatment, at the end, and finally at follow-up. Evaluators at these organizations also need to differentiate when to use parametric and nonparametric tests. Again, reinforce that the outcomes data or dependent variables when scaled at an ordinal or nominal measurement 
level requires using a nonparametric test. Similarly, the actual distributions are rarely normally distributed in these data sets (Micceri, 1989) and therefore are best analyzed using a comparable nonparametric test.

Improve likelihood of identifying significant differences

The third problem will be a bit more abstract for your students, the likelihood of committing type II errors. The two most common reasons include using too small of a sample and applying the incorrect test of significance. To encourage that students gain an introductory understanding of inferential and just as importantly non-parametric statistics, you may encourage them to use the MS Excel Stat Tool Pak on their computers. While obviously not as flexible as more advanced packages such as SPSS or SAS, the package is available to virtually anyone at anytime. As these individuals are instructed on more advanced methods, one must not rush into teaching only empiricism at the expense of constructs (Resich, 2000) and the student's ability to think critically.

\section{Conclusion}

Two vital issues must be addressed as the next generation of quantitative researchers and evaluators are prepared to enter into education and social service. Because organizations are asked frequently to conduct evaluations using small samples, and the data from these distributions usually are non-normal, these future leaders need to receive sufficient instruction on the methods most appropriate for dealing with these concerns. Therefore, methods must be provided to link robust methods for organizational (social service and educational) decision-making. As a frequent user of modern statistical methods, the intention of this article is not to disparage our tremendous strides, but rather to suggest that in preparing the next generation of educational and social service decision-makers there must be balance. This may best be achieved through reinforcing the students' knowledge of why repeated measures are more powerful especially given limited samples.
One noticeable and encouraging trend within these organizations is the continually improving and increasing use of information technology that assists in doing a better job of measuring positive changes in their clients' outcomes. This increasing use of evidence to support the design and implementation of interventions may be related to recent developments of evidence-based practice whereby planners and administrators of services identify relevant information for choosing the interventions they provide. Evidence may be in the form of scholarly journal articles, programs having been identified as best practice, and comparing outcomes of program interventions to state and national norms, to name but a few.

These future decision-makers must be assisted with the data they collect and process for organizations to ensure they use appropriate statistical methods so as to minimize the likelihood of producing Type II errors. Researchers need to encourage the use of more robust methods in the statistics and methodology classes in order for their students, who eventually become leaders within these organizations, too become familiar and comfortable in their use. Encouraging students to use these elementary and powerful statistical approaches will assist them in justifying future funding.

As governments increase their efforts to identify educational improvements in student achievement vis-à-vis programs such as No Child Left Behind (US Department of Education, 2002), or as child and family service organizations attempt to demonstrate macro level improvements in the outcomes of children, through the US Department of Health and Human Services Child and Family Service Reviews - real change often occurs at the smaller organizational unit. One possible avenue to explore with these students is the use of complexity theory. Although applications remain rare in educational and social services (Hudson, 2000, Proehl, 2001), complexity theory has in recent decades evolved within the natural sciences. As the assumptions pose significant challenges (Patton, 2002), providing students with a framework for applying a complexity approach at a minimum should include reviewing the components of a complex 
system. These components include identifying the agent (student or consumer of services), the different choices that the agent can make, the dynamics within the environment, the availability of a feedback mechanism to assist in decision-making, an underlying organizing structure within which all these phenomena occur, and the resulting emergent behavior or outcome.

\section{References}

Batcher, M. (2005). Results of the focus groups on accreditation. Amstat News. No. 337, 18-19.

CARF: The Rehabilitation Accreditation Commission (2005). Behavioral Health Accreditation Standards Manual 2005-2006, 5160. Tucson, AZ: CARF.

Hudson, C. G. (2000). At the edge of chaos: A new paradigm for social work? Journal of Social Work Education, 36(2), 215-230.
Micceri, T. (1989). The unicorn, the normal curve, and other improbable creatures. Psychological Bulletin, 105, 156-166.

Patton, M. Q. (2002). Qualitative research and evaluation methods. Thousand Oaks, CA: Sage.

Proehl, R. A. (2001). Organizational change in the human services. Thousand Oaks, CA: Sage.

Reisch, M. (2000). The future of doctoral social work education in the United States: Questions, issues, and persistent dilemmas. Journal of Social Work Education, 36(2), 57-71.

United States Department of Education (2001) No Child Left Behind Act. Website http://www.ed.gov/nclb/overview/intro/index.ht $\mathrm{ml}$ Washington, DC. 